\title{
Does Automation of the Accounting Profession Affect Employability? An Exploratory Research from Lebanon
}

\author{
Hassan Rkein, Zeinab A. Issa, Farah J. Awada, Hussin J. Hejase* \\ Faculty of Business Administration, Al Maaref University, Beirut, Lebanon \\ Email: ^hhejase@mu.edu.lb
}

How to cite this paper: Rkein, H., Issa, Z.A., Awada, F.J. and Hejase, H.J. (2020) Does Automation of the Accounting Profession Affect Employability? An Exploratory Research from Lebanon. Open Journal of Business and Management, 8, 175-193. https://doi.org/10.4236/ojbm.2020.81011

Received: October 15, 2019

Accepted: December 20, 2019

Published: December 23, 2019

Copyright $\odot 2020$ by author(s) and Scientific Research Publishing Inc. This work is licensed under the Creative Commons Attribution International License (CC BY 4.0).

http://creativecommons.org/licenses/by/4.0/

\begin{abstract}
Technology advancement and automation of job functions will impact negatively numerous job categories, among these are accounting jobs. This paper aims to qualitatively assess the impact of automation of the profession of accounting on employability by conducting a qualitative research using semi-structured interviews with a convenient sample of Lebanese employees, employers, instructors and students who were willing to participate and offer their insights. For that purpose, a literature review is first conducted to build the theoretical platform followed by pinpointing what researchers have contended about the impact of automation. Findings of this research suggest that respondents were aware of the fact that specific accounting jobs will disappear though new jobs may substitute the aforementioned specially jobs that necessitate skills such as critical thinking and consultancy. Findings, as simple as these are, are used as initial indicators to shed light on the impact of automation on Lebanese management and policy makers in private and public institutions as well as universities. Other researchers may benefit by conducting more in depth qualitative and/or quantitative analysis to generalize the outcomes.
\end{abstract}

\section{Keywords}

Automation, Accountancy, Unemployment, Lebanon

\section{Introduction}

Automation has always raised concerns on the job market as it has become a central issue. Though economic development aligned with the advent of new technologies has affected many professions with time leading to unemployment, yet the unemployed may be attracted by newly created sectors ([1] [2] [3]). 
History shows that the adoption of technological innovation can act as a powerful stimulus on the economy, employability, and job creations and particularly accountants. It can as a result be argued that the overall effect of computerization and mechanization has been to create jobs at an unprecedented rate. In specific, as firms gain scale, they require more managers, accountants, and other administrative employees [4] (p. 37).

Many workers in occupations with high educational requirements who spend much of their time collecting and processing data could experience a significant shift in their work activities. According to Perisic (2018) [5], though accountants are among the professionals whose jobs are in decline during the last five years, on the other hand, account managers will be demanded. For example, account/financial managers could spend less time monitoring cash flow or approving expenditures, and instead have time to focus on more managerial functions such as supervising employees and advising others on business matters.

This aforementioned becomes significantly crucial in a country like Lebanon, where already jobs are not extensive, as well as all other third world countries, where governments are not much proactive about the fast track of technology and the quick changes on professions and consequently the demand for new competencies to mitigate unemployment incidents. However, before going forward to the next section, it is necessary to review the status quo of the Accounting major students in Lebanon by shedding light on the student population graduating annually by addressing business students in general and accounting students in particular.

\subsection{The Lebanese Accounting Human Capital}

Lebanon has a very developed and significant private Higher Education sector. It represents more than $60 \%$ of the total student enrolment in Higher Education [6]. According to Hejase and Alaeddine (2017) [7], "the last two decades witnessed Lebanon's active move to make significant progress to elevate its education and academic standards" (p. 27). Lebanon exhibits tremendous gains in terms of more equitable access to formal education [8] (p. 3). The literacy rate among youth females surpasses that of the youth males, countervailing the dominance of literate male adults over female adults at $93.50 \%$ and $86 \%$ [8] (p. 3). The aforementioned has been possible due to the efforts of the Ministry of Education and Higher Education (MEHE) which adopted an aggressive role to realize significant improvements and reforms at all levels of the youth schooling, from primary schooling to secondary education making education accessible to every child.

Today Lebanon has beside the only public university, the Lebanese University, 35 private universities, 9 institutes and colleges, 3 institutes for religious studies, and 2 other universities which hold official decrees but did not start their operations yet [9]. The number of university students in Lebanon during the academic year 2017-2018, including undergraduate and graduate students, amounts to 210,720 students where the private universities hold 131,360 students in all the 
aforementioned universities [62.34\%], whereby the Lebanese University holds 79,360 students [37.66\%] [10] (pp. 86-98). As for the students who elected to pursue their degrees in Business and Economics [which include Accounting], there are 7291 students in the Faculty of Economic Studies and Business Administration at the public university, while there are 34,689 students in all the private universities classified as Commerce, Business Sciences and Law [10]. Usually students who are pursuing their degree in Accounting and related fields form $3 \%-5 \%$ of the total population of business students (personal communication with chairpersons and full time Accounting instructors in 8 universities). Therefore, Lebanon has approximately 1680 [4\% average] Accounting students who compete for the available jobs in the labor market when graduated every year. Not to forget the graduates holding the Vocational Baccalaureate whose number is 328 in 2017-2018 academic year [10] (p. 79), which increases the number of students holding the Accounting major to 2008.

The available research papers in Lebanon dealing with accounting graduates actually address the issue of gaps between Accounting Education and Practice ([11] [12] [13]). As far as the authors' knowledge about the topic under discussion, none addressed the issue of automation impact on employability. However, the nearest issues addressed by Hakim [11] and Majzoub \& Aga [12] relate to curriculum weaknesses. More specifically, Hakim [11] contends that "Accounting students in Lebanon are found to be inadequately prepared in technological skills and applications" (p. 14). On the other hand, Majzoub and Aga (2015) [12] assert that "There is a gap in both technical and professional competencies: When Accounting professionals are asked to evaluate the technical competencies (accounting and generic which include Information Technology applications) of fresh accounting graduates, they rank all of these competencies below average; ... Furthermore, our surveys show that the employer's evaluation of the professional competencies of recent graduates is acceptable, while the students over-estimate their own professional competencies" (p. 145). Moreover, according to Dibeh et al. (2016) [13], "employability and skill mismatch are jointly determined in the youth labor market” (p. 9).

\subsection{The Lebanese Employment Status}

International Labour Organization (2015) [14] contends that "the Lebanese labour market is encountering significant challenges. In 2012, the national unemployment rate was estimated at 11 per cent, with jobseekers often unemployed for periods of up to one year. Unemployment rates are particularly high for women (18 per cent) and youth (34 per cent)" (p. 1). Furthermore, according to Dibeh, Fakih and Marrouch (2016) [13], "despite some efforts by the government to tackle the problem of youth unemployment in Lebanon, the unemployment rate remains among the highest in the world. Research shows that the youth labor force participation rate in Lebanon of $29.1 \%$ is the lowest in the world compared to all economic regions. In addition, it is lacking behind the average of the MENA countries. Overall, these statistics are alarming and raise ur- 
gent labor policy questions that should be among the top priority items in policymaking in the country" (p. 2).

Therefore, amid the grim picture described first by high unemployment rates and second by the fact that "employers find that accounting graduates are not being adequately taught generic skills in their universities" [11] (p. 4), the subject of this research presents the possible concerns for the future of the Accounting profession whereby automation and the use of Information Technology applications are among the skills that are not very well addressed in the Lebanese Accounting curricula in different universities.

In addition to the aforementioned, and since the accounting profession has been over the past thirty years impacted heavily when computers and new application software substituted the functions of certain jobs labelled routine like bookkeepers and cashiers to a large extent, this unique paper has the objective to raise awareness and shed light on the current attitude of a selected number of both Accounting students and professionals in Lebanon towards automation. Of specific interest and concern is the availability of employment and future challenges.

\section{Literature Review}

O'Neill (2016) [15] contends that "the driving motivations behind the installation of Artificial Intelligence (AI) in business processes appear to be the greater speed, accuracy and volume capability of computers when compared to their existing human counterparts" (Para 6). For example, "Kensho" is an intelligent computer system widely used by stock traders and investors to automatically analyze portfolio performance and predict market changes [15] (Para 7). Another example, Vasarhelyi and Rozario (2018) [16] asserts that Robotic Process Automation (RPA) erupted a disruptive change in the traditional auditing practice, since it automated repetitive tasks, it provided an opportunity to improve audit quality, business processes and services offered by accounting firms. This will allow auditors as a result to operate at a much higher level, by releasing their time for more significant work. Furthermore, O'Neill (2016) [15], clarifies that the new competencies demanded by automation have opened new fields of application, one potential competency is "predictive analytic" which "allows for the automation of evidence gathering and the production of complex data reports, saving time and improving client services" (Para 18).

Though the aforementioned examples support the notion that automation brings forward new applications and competencies, other researchers are not so much optimists. Nagarajah (2016) [17] quoting the "Financial Times" stated that "artificial intelligence tools are increasingly being used to replace the work done by new graduates, leading to expectations of a significant drop in the employment of graduates by these companies" (p. 35). However, automation conjures up an image of a machine replicating the activities of a human doing the work. People are irreplaceable, especially at higher levels. "Systems and technology ad- 
vance, will never replace human beings who can strategize, influence and work with major stakeholders to improve finance and business performance overall," said Tom Osborne, Regional Director of Hays Malaysia [17] (p. 37). At the end of the day, automation is still nascent but accountants should be prepared and flexible.

Here we discuss the influence of automation on accounting firms, there appear to be five areas that are worth to be highlighted on:

Törnqvist and Forss (2018) [18] (pp. 51-57), in their research, defined several impacts of automated accounting on the accounting firms and the accounting consultants. Table 1 provides a summary of their findings.

Table 1. Impacts of automated accounting on the accounting firms and the accounting consultants.

\section{Change in Tasks}

As a result of automation, many accounting consulting tasks can now be performed automatically, reducing the manual work of accounting for the consulted. However, the accounting consultants are allowed to focus on analytical services instead. Therefore, consultants will have more time for customers and their business. Consequently, advisory services have already increased in recent years, since automation has become more in the tasks of daily work.

\section{Efficiency}

The implementation of automated processes in the business can lead to several positive effects. Through automation and corresponding decrease in manual handling, the consultant is allowed to work more efficiently.

\section{Client Relation}

The Associate Accounting consultants do not see the development of automated processes as negative. Through automation, new services will emerge as for a consultant and much more advanced and beneficial services can be performed this will result in expanding the list of clienteles. Through new services, especially advanced consulting services, personal contact with customers will grow and become more important. According to (Sun Lu, 2017) [19] (pp. 1-2), irrespective of how far automation may reach, a human can never be totally replaced by computers. Scientists state that computers and programs are not enough to develop tasks as analyses or interpretations, where therefore a human being is needed.

\section{IT-Problems}

Sun and $\mathrm{Lu}$ (2017) [19] (pp. 1-2) argued that today's computers and programs are not good enough. However, the confidence in automation is in shortage, and accounting consultants still see the risks of misstatements as a contemporary problem. Moreover, the shift to automated accounting will also give the accounting process a greater dependability on Internet connection, electricity, less malfunctions of systems and safety. A problem that consultants have encountered is the disconnection of the Internet and lack of electricity, which delays the process where accountants aren't able to perform their duties.

Regarding the safety issue, where Dimitriu and Matei (2014) [20] (pp. 239-240) and Ionescu and Prichici (2013) [21] (p. 284) argued that hacker attacks would cause a significant damage to accounting firms in terms of data loss and disruption.

\section{Job Opportunities}

As Frey and Osborne (2017) [22] (p. 278) from the Swedish Foundation for Strategic Research have emphasized, automated accounting will result in loss of employment. Many argued that automation leads to fewer people participation in the process. It is also argued that the repetitive tasks are the ones that will face the greatest risk of being replaced by automation, which are often assigned to accounting assistants. For example, Nagarajah (2016) [17] (p. 35), contends that Accounting consultants with less experience in the profession or accounting assistants are perceived in the risk zone to relinquish. Furthermore, researchers Goos and Manning (2007) [23] (p. 118) and Shim and Yang (2018) [24] (p. 144) warn that the middle educated category of employees are pushed out of their profession, unless they find a more cognitive orientation to keep their jobs.

On the new competencies front, cognitive tasks are "often done by a senior accountant or more experienced professionals, whereby these professionals are safe from being replaced even in the future" [18] (p. 55). However, few still believe it is only a matter of time when computers are able to do part of these tasks. With the increased use of automated accounting, fewer hours of accounting process will be given, thus reducing the number of jobs opportunities. 


\section{Attitudes toward Automated Accounting}

As has been deliberated, there is a mix feeling about automation among accounting professionals. Some accounting consultants believe that it would be difficult to convince others to provide automated operations in their daily work. Furthermore, removing the negative attitude spread out, as well as the distrust towards the systems, makes others express criticism. However, recently there are more researchers who point towards the positive outcomes. One of the key factors that made Accountants point to a positive attitude is the fact that automation will facilitate their daily work. Nagarajah (2016) [17] (p. 37), for example, stressed that automation gives professionals more time to be strategic and become true business partners. Villanova (2019) [25] (Para 3), stresses on the fact that "machines will unlock an accountant's ability to share their judgment, enriching their employment experience and perceived value within the organization". Furthermore, instead of having to focus on detecting problems after occurring, financial controllers may now be able to anticipate those problems before they occur based on big data patterns. "It's what organizations do with the data that matters. It can be analysed for insights that lead to better decisions and strategic business moves. That is what makes big data relevant to the accounting profession" [26] (Para 3).

\section{Methodology}

The purpose of this research is to assess if automation of the accounting profession affects employability? However, to the best of the researchers' knowledge there is not much about this subject in the academic research in Lebanon. For that, primary data is needed to be collected from the field. Hejase and Hejase (2013) [27] contend that "through exploratory research, a researcher acquires deeper knowledge as to how to convert the problem of not having facts about the subject into a structured one" (p. 80). Therefore, this research uses an exploratory qualitative approach to gather primary data necessary to shed light and assess the declared purpose of this research.

The impact of automation on the accounting graduates employability comes with much uncertainty, and making future projections is complicated, and thus it is difficult to evaluate such impact. For this reason, the researchers chose to adopt a qualitative approach rather than quantitative approach, because collections of statistics and number crunching are not the best approach to reveal uncertainties and do not assist in understanding meanings, beliefs and experience. These are better understood through qualitative studies.

Having decided on an exploratory and qualitative research approach, the research tool adopted is semi-structured interviews. These are inductive in nature and are seen as a respectful way to obtain information from university participants. According to DiCicco-Bloom and Crabtree (2006) [28], "semi-structured interview use a guide, which is a schematic presentation of questions or topics and need to be explored by the interviewer" (p. 315). 


\subsection{Sampling}

This study was set out to determine possible impacts that automation may have on accounting graduates employability. In order to address this issue semi structured interviews were conducted with four different sources of information as follows:

1) Accounting Employers

2) Accounting Employees

3) Accounting Instructors

4) Accounting students

The population for a full-fledged research on this topic includes all Accounting graduates (estimated earlier as 2008, University instructors (based on 25 students to 1 instructor then the number is 80 full timers matched by a rate of 8 part timers to each full timer 640 or a total of 720 , professionals (including certified individuals or 1680 [29] to 2000 persons), and employers in the Lebanese economic market. $95 \%$ of the Lebanese companies are labelled Micro, Small and Medium enterprises employing $50 \%$ of the Lebanese labour force. There are 70,062 registered companies [30] (p. 11) and assuming one head for the Accounting department. Therefore, the total population amounts to 74,790 individuals. Now, using the Yamane (1967) [31] formula, we get the sample size of 398 individuals required for a quantitative analysis with 5\% standard error (95\% significance). However, since this is an exploratory qualitative study a sample of 20 persons may be sufficient to shed light on the subject under research taking into consideration the limitation of not being able to generalize data.

20 participants in all were chosen from the Accounting profession and major. Five persons per each category were approached.

Codes utilized herein for participants in this study are as follows:

1) Employers are represented by the letter $C$,

2) Employees are represented by the letter E,

3) Professors are represented by the letter I,

4) Students are represented by the letter $S$.

Participants were selected based on their willingness to offer the researchers their valuable time and enthusiasm to discuss in depth their experiences, opinions and worries for the future. All participants were informed about their role and the confidentiality of their responses, that is, no names will be revealed and responses will be only used for the research objectives. The selected individual's demographics are as follows:

5 employers selected from 5 Accounting firms in Greater Beirut Area.

5 employees ( 2 in accounting firms, 1 in Hospital, 1 in University, and 1 in private business).

5 professors (1 in Al Maaref University, 1 in American University of Science and Technology, 1 in Beirut Arab University, and 2 part timers).

5 students (1 from Al Maaref University, 1 from Beirut Arab University, 1 from Lebanese American University, 1 from University of Sciences \& Arts in Lebanon, and 1 from Lebanese International University) Table 2. 
Table 2. Sample demographics.

\begin{tabular}{|c|c|c|c|c|c|c|c|c|c|c|}
\hline \multicolumn{5}{|c|}{ Employers [C] } & \multicolumn{6}{|c|}{ Employees [E] } \\
\hline Age & Gender & \multicolumn{2}{|c|}{ Education } & Yrs. Exp. & & Age & Gender & Education & Yrs. Exp. & Firm \\
\hline 52 & Male & \multicolumn{2}{|c|}{ MBA, CMA } & 20 & 1. & 25 & Male & BS & 3 & Private \\
\hline 46 & Male & \multicolumn{2}{|c|}{$\mathrm{CPA}$} & 15 & 2. & 36 & Male & MBA & 11 & University \\
\hline 43 & Female & \multicolumn{2}{|c|}{$\mathrm{CPA}$} & 18 & 3. & 38 & Female & MBA & 10 & Acct. I \\
\hline 38 & Male & \multicolumn{2}{|c|}{ MBA } & 12 & 4. & 27 & Female & BS & 6 & Hospital \\
\hline 29 & Female & \multicolumn{2}{|c|}{$\mathrm{PhD}$} & 6 & 5. & 43 & Male & MSc, CMA & 15 & Acct. II \\
\hline \multicolumn{5}{|c|}{ Professors [I] } & \multicolumn{6}{|c|}{ Students [S] } \\
\hline Age & Gender & Education & Yrs. Exp. & Univ. & & Age & Gender & Education & Yrs. Exp. & Univ. \\
\hline 33 & Male & $\mathrm{PhD}, \mathrm{CPA}$ & 6 & MU & 1. & 20 & Male & $\mathrm{BS}\left[2^{\text {nd }} \mathrm{Sem}\right]$ & - & MU \\
\hline 41 & Female & $\mathrm{PhD}$ & 18 & LAU & 2. & 19 & Female & $\mathrm{BS}\left[2^{\mathrm{nd}} \mathrm{Sem}\right]$ & - & AUST \\
\hline 44 & Female & $\mathrm{PhD}, \mathrm{CMA}$ & 20 & BAU & 3. & 21 & Female & $\mathrm{BS}\left[3^{\text {rd }} \mathrm{Sem}\right]$ & - & LAU \\
\hline 46 & Male & MBA, CMA & 20 & $\mathrm{PT}$ & 4. & 23 & Male & BS & Working & 2 USAL \\
\hline 32 & Female & $\mathrm{PhD}$ & 6 & PT & 5. & 27 & Female & BS & Working & $4 \mathrm{LIU}$ \\
\hline
\end{tabular}

* Part time Professors: PT, teaching in more than 2 Universities.

\subsection{Interview Design}

Four different semi-structured interviews were designed. C were asked 14 questions covering awareness about automation and its applications, costs, effects, and impact on recruitment for future accounting personnel needs. E were asked 8 questions covering awareness about automation and its effects, new applications at work, and impact on the job performed. I was asked 13 questions covering awareness about automation and its applications, curriculum issues, impact on students' competencies and impact on the profession. Finally, $\mathrm{S}$ were asked 10 questions including awareness about automation and its applications, effects on the profession, effects on the curriculum and concerns about employability in the future.

\section{Findings}

By the end of the lengthy and time consuming interviews with the four sources, whereby one hour and half was dedicated to each interview, to better present a concise and comparative results to understand the possible impact of automation on accounting and on the graduates' employability, nine issues were found to be common and worth noting as depicted in Table 3.

The next section provides a summary of the outcomes as divided based on the aforementioned subjects. Though findings are depicted in Table 4 showing the contribution of each type of participants (Tables 5-11).

\section{Discussion and Implications}

This research aimed to assess the impact of automation on the Accounting profession and the fresh graduate's employability. Findings support that not only graduating students are concerned but all other participants as well, though outcomes suggest that awareness about automation as related to the accounting profession is high. Employers, employees, instructors and students are actually 
utilizing accounting software applications to different degrees and at the same time are highly aware about the future changes which will necessitate proactivity to get ready with new competencies which will be highly necessary to join the workforce with high literacy about IT applications.

Table 3. Major subjects addressed by the interviewees.

1) Artificial intelligence (AI) and Accountant's tasks,

2) Comprehensive automation,

3) The Cost of Automation,

4) Participants' attitudes toward automation,

5) Advantages and disadvantages,

6) IT and Accounting,

7) Modern Recruiting Strategy,

8) Graduates preparation,

9) Automation versus Employability

Source: Rkein et al., 2019 [32].

Table 4. Findings: Automation and accountant's tasks.

The following observations were recorded:

I:

1) Full awareness about automation in all its forms

2) Ability to pinpoint how artificial intelligence (AI), Information and Communication Technology ICT and specific accounting software applications are reforming the curriculum and the future consequences on particular accounting professions.

Evidence statements:

"Automation or artificial intelligence or the inclusion of big data and cloud computing or bringing in technology into the accounting world, isn't something new"

"Automation is something that started years ago, and this has resulted in opening opportunity for the accountants ... P"

"70\% of the work that's actually done in the Middle East or in Lebanon, now is the type of work that would for instance be eliminated if automation takes place in this market."

E:

They confirmed the aforementioned whereby they explained the relation between accounting and AI, giving examples such as: "sending recurrent invoices to customers when subscription period requires renewa?".

S:

1) They were aware of automation from their Accounting Information Systems course in their curriculum.

2) They unanimously were worried about employability, however they emphasized that they were trained on popular software applications needed in the next 5 years in Lebanon.

3) They were concerned that automation could make their preferred role redundant in 20 years.

C:

They as well as others agreed that developed accounting software won't replace human beings, it facilitates the accountant's work. However, it may reduce employability.

Evidence statements:

"The accounting office that requires three accountants to do the bookkeeping, now in the presence of accounting software, only one accountant can accomplish it".

"Automation came as a supporting party for accountants rather than being an alternative and surrogate for them".

"Automation reduced most of the redundant work and the repetitive type of work that the entry level accountants used to do." 
Table 5. Findings: Comprehensive automation.

\section{I and E:}

1) Agreed on one statement stating that "we can't automate everything. This is a debate not only in the accounting field, because software, computers ... lack the human factor. So, no we cannot achieve $100 \%$ automation”.

\section{I and C:}

"We will always need that accountant, the one who critically think, analyse, communicate, have ethics, it will only be those repetitive tasks to be automated and which's basically called bookkeeping".

\section{I, E and C:}

1) All agreed that repetitive tasks will be the first to go.

2) The use of cognitive skills like judgement is highly needed.

Evidence statements:

"Nowadays, when a company purchases an asset, an accountant should estimate the useful life, it is a matter of judgment, the accountants give data to the system based on their own judgment."

\section{C:}

"Automation doesn' t mean to dispense of the person who is working, at the end, he is the one who is offering the right data which without it no results to be produced, for that reason there will be no $100 \%$ automation in the future."

S:

They manifested high worries of full automation and their responses were divided as " 3 highly concerned and 2 somehow concerned" when addressing the concern that automation could make their preferred accounting role redundant in the next 20 years.

Table 6. Findings: The cost of automation.

\section{E, I, C, and S:}

1) They viewed the money spent on the process to automation as capital expenditure.

2) A financial feasibility study must be performed to ensure that costs do not exceed the benefits.

\section{I, $S$ and $C:$}

They agreed that "the software is an investment as any fixed asset that you invest in the business".

\section{C, 2I and E:}

"Although we most likely are saving money when we use accounting software, we have to see the costs that are also associated with this, such as the cost of the person who will be operating it"

"It is expected that costs of new competent accountants to be higher since they are highly skilled"

"More costs including maintenance, depreciation, accessories, update and security software."

Table 7. Findings: Modern recruiting strategy.

\section{I, C, E:}

Automation might also come with new recruiting needs and requirements, and therefore new skills and competencies.

Evidence statements:

"It is not necessary for candidates to be expert in all types of accounting software, since once they are hired, they will be trained for the software that the company adopts."

C:

"Our companies make sure to train and prepare all our accountants with new software skills."

"Our recruitment strategy is on the move to locate graduates who are prepared for the future."

S:

"Our University is preparing us to be familiar with at least two popular accounting software used in the Lebanese workplace." 
Table 8. Graduates preparation.

\section{I and C:}

1) Automation requires the university accounting programs to take the new technology into consideration.

Evidence statements:

I:

"Most of the universities are aware of this point and are preparing students to be able to face it. Although we don't have time to apply software system courses, still there are many workshops and trainings, that students are recommended to attend".

"For a while now, students in good universities are exposed to accounting software that are actually available in the market and usually most universities have in their program a course called "Accounting Information Systems-AIS".

C:

"The market wants universities to train students on accounting software and this is one of the challenges that the market and the employers usually face with fresh graduates, that they know the technicality but they haven't used the software yet".

\section{I and E:}

University accounting programs are not yet developed to prepare students for such new world that surpassed the software system and have been taken over by cloud computing.

Evidence statements:

"Most of the markets are not up there yet, so if universities want to prepare Lebanese students and train them on such platforms, students will go out to the market which is still not aware of it, so graduates may be ahead". This raises the debate on the role of the universities that can be played in reshaping the industry.

Participants of all four categories [I, E, C and S], seem to agree that Lebanese students will not benefit much from the amended accounting programs, because the market is not yet able to respond to these expertise and skills, since it is not equipped for an environment of cloud system and artificial intelligence as in the west. For instance professors think that in general, "students in Lebanon are not getting prepared for it, for two reasons. first, universities lack the expertise to prepare for them, second is that the market is not there yet".

Table 9. Attitudes toward automation.

\section{Evidence statements:}

C:

"Employers in Lebanon are all obliged to know about accounting automaton, or else, they will be out of business."

"Recently, most CPA firms in Lebanon are adopting new accounting information system techniques because their clients are already adopting accounting systems; and in order to be able to deal with them and perform their services, they should adopt these software technologies."

"When we live or work in a fully automated and computerized environment, we are enforced to engage in, otherwise, we may be forced out of the market by new competitors who are smarter in technology than us".

E:

"Employees consider that accounting automation is good in principle."

"Technology makes life much easier".

"Accounting automation allows for better use of human brain rather than sticking in the minor role as for just counting numbers. Accountants can work on more advanced and strategic levels".

\section{I and S:}

I:

Professors highlighted on their teaching experiences with students and their first attitude toward automation, software, artificial intelligence and the cloud systems. They think that "if students have been exposed to automation, particularly accounting automation, through their books, lectures, workshops and seminars; they will perceive it differently than if they were not aware of it at all."

"Students at this stage see it from a long distance as a threatening, they do not see it as an opportunity and that is because of the existing tough market”.

S:

"We read about automation in our textbooks and reports or heard of it from their instructors."

"We believe automation is a threat since we are not getting prepared properly for it at the university." 


\section{Continued}

Clients from the point of view of employers [C]:

"The client knows that his services will be done via software and systems, his confidence and trust in the outcomes will increase".

Before automation: "when the client used to ask for his reports and findings, we were not able to afford it in a short time, since there are several operations to go through including the comparison of balances, etc..."

After automation: "Today, tasks turn to be more efficient ... employees accomplish their duties in no time, and this has a great impact on preferred clients who were the first to welcome this intervention". One employer also stated, that "reports' design and style we now produce are neater, clearer, well arranged, organized and professional than before".

"Nowadays, with the new technology and data backups, there is less chance for the data to be lost, which used to happen when the accountants relied on one server or PC in their office, but today the new system came to preserve information. Now people especially clients have extra trust and confidence to the accounting software".

Table 10. Advantages and Disadvantages.

\section{Disadvantages:}

1) I: "there is a race between technology and the claim that it will create more jobs. Technology is always running in a faster rate than the expectations to generate jobs' opportunity.”

2) I: "Though it is stated that accounting automation will help the accountant elaborate and extend the scope of his/her thoughts, abilities and to have the opportunity to shift to the upper stages of accountancy; unfortunately, we see that there are no job's offerings regarding the strategic roles out in the market."

3) I: "In Lebanon, an employer's self-interest may choose to go for automation such as. (software and cloud computing) in the company if they see the benefit exceeding cost, indifferent of whom is going to be kicked out".

4) $\mathrm{C}$ and E: "Due to automation in the accounting era, businesses may face several challenges as for. manipulation in the cloud system, penetration in security system, and the market will have an increase in the unemployment rate".

5) C: "If you are working on a personal computer that stores all your information and you did not make a backup for it, the data will be lost."

6) I and C: "if organization's current employees are not familiar and with no background of the new software, the employer has to plan and execute training sessions which will cost the business instead of saving money as what is hoped".

\section{Advantages:}

1) I and C: "Many graduates are going to find jobs easily, and achieve objectives timeliness and will have enough time to spend on the analysis aspect".

2) C: "There are many improvements and changes that have emerged due to this automation, the most significant to be mentioned are: time saving, less usage of papers".

3) I, C and E: "accounting isn't just about data entry; accountants make reports and have the time to move to analysing. Thanks to automation today, we are able to bring the oldest information and compare them to the current information".

4) E and C: "The level of performance of the staff increases as they deal professionally and on international level as for working on the accounting programs and the information system. This is embedded through the quality of the reports we produce, where the reports address more professionalism".

Table 11. Automation versus employability.

C:

They consider that automation limits job opportunities.

Evidence statements:

"In the past, organizations needed five to six accountants to accomplish their duties, today by the presence of automation only one or two accountants are enough."

"It is certain that this phenomenon is going to lead an increase in unemployment especially amongst the fresh graduates".

\section{C, E and I:}

1) It is possible for automation to replace simple tasks in accounting, but as an actual benefit to accountants, automation is considered to be as a third hand for the accountant but never replacing him/her or even affecting his/her career.

2) Accounting graduates shouldn't be concerned regarding this, jobs can be found.

3) Information technology is no longer distinct from accounting field.

Evidence statements:

"Students are now more than any time before are required to improve their IT skills to survive in the digital world." 


\section{Continued}

S:

1) They were concerned.

2) Automation opens opportunities.

3) Appreciated that their universities are preparing them to acquire current theoretical as well as practical knowledge of how their accounting career is enabled with software applications.

4) Complained that they are not trained on cloud computing applications.

Evidence statements:

"We think there will be less jobs ... already students do not get jobs easily when they graduate, so imagine it with automation".

"Working on ourselves and acquire the skills we will be able to distinguish ourselves from the many other graduates and we can then secure employability"

This research, though exploratory, is considered one of the very few conducted in Lebanon and a new addition to the current scarce knowledge about the subject not only in Lebanon but also abroad. The outcomes are encouraging motivating other researchers in Lebanon as well as the region run similar studies to create a clearer view about the awareness of the impact of automation about the different accounting jobs and the readiness of the Lebanese and the regional job markets to deal with advanced needs for accountants and auditors who are prepared to be informed consultants and strategists. Amid the grim scenario of the Lebanese job market whereby there is a clear gap between graduates' competencies and those needed by the job market, and recognizing the differences among universities to prepare their Accounting students with respect Information Technology applications, the outcomes of this research are still valid because researchers are recommending universities to review their curricula in order to cope with future requirements including automation ([7] (p. 35) [11] (p. 14) [12] (p. 145) [14] (p. 8)).

\subsection{Impacts of Automation}

With the reminiscence, this research was able to expose two theories regarding this debate.

\section{Impact of Automation on the Accountant's Role}

Four of the respondent employers support Lupasc's et al. (2012) [33] claim that accountants are today allowed to focus more on analytical services as manual entries and tasks are no longer needed. Employers and professors believing that as automation replaces the redundant, repetitive and entry level tasks, as contended by Uwadiae (2015) [34] and Frey and Osborne (2017) [22], the accountant has the opportunity to work more on his/her cognitive, critical thinking skills and ethical values. The remaining fifth employer had a different view stating that the accountant does not go into accounting analysis but goes further to check for errors in the journal entries.

Furthermore, Alarcon and Staut (2017) [35] (pp. 3-4) and Villanova (2019) [25] (Para 3) highlighted that critical thinking and judgement has increased in recent years, since automation has become more in the tasks of daily work, a fact confirmed by the interviewee professors who contended that "those who used to 
do manual work are going to move up to work on more strategic things, and that those who already work on strategic levels will move up to higher levels this is the hope."

\subsection{Client Relation versus Automation}

This research's findings and the interview outcomes show that none of the respondents fully agreed that human beings are not needed any more as automated processes continue to develop as well as computers shall perform accountants' future tasks, a fact that impacts clients negatively. Instead, interviewees being employers and professors asserted that automation had a positive great impact on accounting firm's clients. Employers capitalized on the virtue of development, accountants are able to communicate with their clients and satisfy their needs even if they are far away from each other, and that is just by sending emails. Worth mentioning that researchers do not fully agree on the aforementioned, rather mix opinions exist. Taipaleenmäki and Ikäheimo (2013) [36] (p. 342) asserted that the relationship with the client will suffer or even go Lost. They claimed that when processes are being automatic, an accounting consultant will be perceived as a computer rather than human being, because most tasks are performed automatically in the system. On the other hand, Sun $\mathrm{Lu}$ (2017) [19] as well as all of the participants in this research, stressed that computers will never replace human beings especially in the scope of critical thinking, analytical skills and the capability to give judgments. Instead AI is there to enable the accounting functions.

\subsection{Efficiency}

One of the most significant advantages that all the participants agreed on, is the increase of efficiency of the accounting firm as automation is implemented. Responses which conform to reported secondary data ([17] [37] [38]). Also, the interviewees' input sustain the fact that instead of reporting and wasting time in writing on paper, putting it in files, and then designing a voucher ..., automation came to abridge all these operations in one double click therefore, tasks will be finished and reported in less time. Ionescu and Prichici (2013) [21] contend that "no matter the size and type of organization but especially for SMEs Cloud provides a competitive advantage by providing access to affordable, reliable and flexible IT solutions, which allows them to operate more efficiently among their competitors in the market".

\subsection{IT and Accounting}

The shift to automated accounting will give the accounting process a greater dependability on Internet connection, cloud computing systems and IT knowledge, where all are interrelated as addressed through this research. Dimitriu and Matei (2014) [20], (2015) [39]), and Ionescu and Tudoran (2013) [40], reflecting a negative feeling, argued that hacker attacks would cause a significant damage to 
accounting firms in terms of data loss and disruption. The same aspect was emphasized by most interviewees saying that any person who intends to steal the data from the computer will find it as a great opportunity to hack the system or even to sabotage it; and pointing out on the lack of control over accounting process and data. However, Ionescu, Prichici and Tudoran (2014) [41] insist that Cloud Accounting [and Accounting Software] would eventually change the accounting profession, leading to an important improvement of the way financial activities will be performed, of the interaction with the clients and of the speed and efficiency of the response to their needs. Furthermore, O'Neill (2016) [16] with an optimist stand stressed that "Predictive analytics allows for the automation of evidence gathering and the production of complex data reports, saving time and improving client services” (Para 21). Furthermore, O’Neill quoting Noah Waisberg, CEO of Kira Systems, hails IT and AI, "Artificial intelligence has arrived to a point where machines can scale human expertise by extracting information from complex documents" [16] (Para 34).

\subsection{Job Opportunity}

Deloitte (2016) [42], report emphasizes that technology in general will likely "create more (and generally better-paid) jobs than it destroys, some industries are likely to lose more jobs to machines than the new technologies will create" (p. 3). However, "businesses and public sector organisations are more likely to spend their time and money understanding how automation can augment their current operating models, as well as the implications for their workforce." Interviewee employers and professors in congruence with other researchers agree on the aforementioned, Frey and Osborne (2017) [22] emphasized that automated accounting will result in loss of employment and that automation leads to fewer people participation in the process, while interviewees, explained that automation takes from the way of entry level and repetitive tasks. However, interviewee instructors and employers argued as well that it is possible for automation to replace simple tasks in accounting, but as an actual beneficial accounting, automation is considered to be as a third hand for the accountant but never replacing him/her or even affecting his/her career, for that reason, accounting graduates shouldn't be concerned regarding this, jobs can be found. Furthermore, optimists like Villanova (2019) [25], stressed on the fact that "machines will unlock an accountant's ability to share their judgment, enriching their employment experience and perceived value within the organization" (Para 3); and Boomer (2018) [26] manifested that instead of having to focus on detecting problems after occurring, financial controllers may now be able to anticipate those problems before they occur based on big data patterns. "It's what organizations do with the data that matters. It can be analysed for insights that lead to better decisions and strategic business moves" (Para 3). Therefore, cognitive tasks such as critical thinking cannot be replaced by automation and that these professionals are safe from being replaced even in the future, this is what all agree on for the long run. Finally, Vermeulen, Kesselhut, Pyka and Saviotti (2018) [43] revealed in their 
research that "potential job loss due to automation in 'applying' sectors is counterbalanced by job creation in 'making' sectors as well in complementary and quaternary, spillover sectors. The study of the several macro-level scenarios on employment, find that mankind is facing 'the usual structural change' rather than the 'end of work"' (p. 1661).

\section{Research Limitations}

Primary data was collected from a very small sample of interviewees, a fact that limits the generalization of the outcomes. However, findings help to shed light on the impact of automation which helps trigger future research on a larger scale. Furthermore, another limitation may be due to the fact that there are four interview designs including different number of questions asked to the four different participant groups, and there could be an impact on the outcomes which is not probed independently. But even though in this case all questions were based on the topics of Table 3 which may provide a common platform, generalization may be affected.

\section{Conclusions and Future Research}

This research found out that almost all participant students were initially concerned with adopting the automation but as soon as they experienced it they were the first to recommend it. Besides, all agreed that automation will not replace $100 \%$ of the accountants, so no need for graduates to fear it, still they can find jobs if they equipped themselves for the outside market. Deloitte (2016) [42] stressed on such an issue in their report emphasizing that "Artificial intelligence has arrived at a point where machines can scale human expertise by extracting information from complex documents" (Para 34). That is, future generation of accounting students must be prepared to "scale their competencies in AI" and therefore proactively join the next generation of the job market workforce. Based on the aforementioned, it is recommended to run a quantitative empirical research across university students in Lebanon majoring in accounting to construct a full view of concerns and assess to what extent they feel confident about their chances of employability.

Furthermore, it is strongly recommended that research must be conducted in Lebanon to assess the preparedness of Universities to modify and implement Accounting curricula that fit the next years of digital requirements and preparing the next generation of accountants' and auditors' competencies.

\section{Conflicts of Interest}

The authors declare no conflicts of interest regarding the publication of this paper.

\section{References}

[1] Pasinetti, L. (1981) Structural Change and Economic Growth: A Theoretical Essay on the Dynamics of the Wealth of Nations. Cambridge University Press, Cam- 
bridge.

[2] Saviotti, P.P. and Pyka, A. (2004) Economic Development, Qualitative Change and Employment Creation. Structural Change and Economic Dynamics, 15, 265-287. https://doi.org/10.1016/j.strueco.2004.02.003

[3] Saviotti, P.P. and Pyka, A. (2008) Product Variety, Competition and Economic Growth. Journal of Evolutionary Economics, 18, 323-347. https://doi.org/10.1007/s00191-008-0097-5

[4] McKinsey Global Institute (MGI) (2017) MGI Jobs Lost Jobs Gained Report. https://www.mckinsey.com/ /media/mckinsey/featured\%20insights/future $\% 20 \mathrm{of} \%$ 20organizations/what $\% 20$ the $\% 20$ future $\% 20$ of $\% 20$ work $\% 20$ will $\% 20$ mean $\% 20$ for $\% 2$ 0jobs\%20skills\%20and\%20wages/mgi-jobs-lost-jobs-gained-report-december-6-201 $\underline{\text { 7.ashx }}$

[5] Perisic, I. (2018) How Artificial Intelligence Is Already Impacting Today's Jobs. https://economicgraph.linkedin.com/blog/how-artificial-intelligence-is-already-imp acting-todays-jobs

[6] Education, Audiovisual and Culture Executive Agency EACEA (2017) Overview of the Higher Education System. European Union.

[7] Hejase, H.J. and Alaeddine, A.H. (2017) Fostering Academic Relations between Lebanon and the Islamic Republic of Iran. The Journal of Middle East and North Africa Sciences, 3, 22-38. https://doi.org/10.12816/0038021

[8] El Khaled, D., Novas, N., Gázquez, J.A., García, R.M. and Manzano-Agugliaro, F. (2016) The Women Education in Lebanon: Lessons for Middle East. Espiral: Estudios sobre Estado y Sociedad, 9, 27-36.

https://www.researchgate.net/publication/301790183 THE WOMEN EDUCATIO N IN LEBANON LESSONS FOR MIDDLE EAST La formacion educativa de la mujer en el Libano lecciones para Oriente Medio Enviar correspondencia a fmanzanouales

[9] Ministry of Education and Higher Education MEHE (2016) Private Universities. http://www.higher-edu.gov.lb/arabic/privuniv/personal univ.html

[10] Center for Educational Research and Development CRDP (2019) Statistical Bulletin 2017-2018. https://www.crdp.org/files/201904031143321.pdf

[11] Hakim, R.R.C. (2016) Are Accounting Graduates Prepared For Their Careers? A Comparison of Employees' and Employers' Perceptions. Global Review of Accounting and Finance, 7, 1-17. https://doi.org/10.21102/graf.2016.09.72.11

[12] Majzoub, S. and Aga, M.A. (2015) Characterizing the Gap between Accounting Education and Practice: Evidence from Lebanon. International Journal of Business and Management, 10, 127-151. https://doi.org/10.5539/ijbm.v10n12p127

[13] Dibeh, G., Fakih, A. and Marrouch, W. (2016) Youth Employability and Skill Mismatch in Lebanon.

http://www.databank.com.lb/docs/Youth\%20employability\%20and\%20skill\%20Mis match\%20in\%20Lebanon\%202016.pdf

[14] International Labour Organization ILO (2015) Matching Skills and Jobs in Lebanon: Main Features of the Labour Market-Challenges, Opportunities and Recommendations.

https://www.ilo.org/wcmsp5/groups/public/---arabstates/---ro-beirut/documents/p ublication/wcms 559673.pdf

[15] O’Neill, E. (2016) How Is the Accountancy and Finance World Using Artificial Intelligence?

https://www.icas.com/ca-today-news/how-accountancy-and-finance-are-using-artif 
icial-intelligence

[16] Vasarhelyi, M.A. and Rozario, A.M. (2018) How Robotic Process Automation Is Transforming Accounting and Auditing.

https://www.cpajournal.com/2018/07/02/how-robotic-process-automation-is-transf orming-accounting-and-auditing

[17] Nagarajah, E. (2016) Hi Robot. What Does Automation Mean for the Accounting Profession?

https://www.pwc.com/my/en/assets/press/1608-accountants-today-automation-imp act-on-accounting-profession.pdf

[18] Törnqvist, E. and Forss, L. (2018) Automated Accounting in Accounting Firms: A Qualitative Study on Impacts and Attitudes. Master's Thesis, Department of Business Administration, Umeå University, Sweden. https://pdfs.semanticscholar.org/9c26/dfea081fd035a6070e382f1b5f0727faa37a.pdf

[19] Sun, Z. and Lu, X. (2017) Fault Detection and Diagnosis System in Process Industry Based on Big Data and We Chat. MATEC Web of Conferences, 139, Article ID: 00008. https://doi.org/10.1051/matecconf/201713900008 https://www.matec-conferences.org/articles/matecconf/pdf/2017/53/matecconf icm ite2017 00008.pdf

[20] Dimitriu, O. and Matei, M. (2014) The Expansion of Accounting to the Cloud. SEA-Practical Application of Science, 2, 237-240.

http://seaopenresearch.eu/Journals/articles/SPAS 4 24.pdf

[21] Ionescu, B.S. and Prichici, C. (2013) Potential Beneficiaries of Cloud Accounting Technology: Small or Large Companies? Change and Leadership, 17, 282-292.

[22] Frey, C. and Osborne, M. (2017) The Future of Employment: How Susceptible Are Jobs to Computerization? Technological Forecasting \& Social Change, 114, 254-280. https://doi.org/10.1016/j.techfore.2016.08.019 https://econpapers.repec.org/article/eeetefoso/v 3a114 3ay 3a2017 3ai 3ac 3ap 3 a254-280.htm

[23] Goos, M. and Manning, A. (2007) Lousy and Lovely Jobs: The Rising Polarization of Work in Britain. The Review of Economics and Statistics, 89, 118-133.

https://doi.org/10.1162/rest.89.1.118 https://www.mitpressjournals.org/doi/10.1162/rest.89.1.118

[24] Shim, M. and Yang, H.S. (2018) Interindustry Wage Differentials, Technology Adoption, and Job Polarization. Journal of Economic Behaviour and Organization, 146, 141-160. https://doi.org/10.1016/j.jebo.2017.11.014

[25] Villanova, P. (2019) Voices: Why Automation Is a Positive Turning Point for Accountants.

https://www.accountingtoday.com/opinion/why-automation-is-a-positive-turningpoint-for-accountants

[26] Boomer, J. (2018) The Value of Big Data in an Accounting Firm. https://www.cpapracticeadvisor.com/firm-management/article/12424744/the-valueof-big-data-in-an-accounting-firm

[27] Hejase, A. and Hejase, H. (2013) Research Methods: A Practical Approach for Business Students. 2nd Edition, Masadir Inc., Philadelphia.

[28] DiCicco-Bloom, B. and Crabtree, B.F. (2006) The Qualitative Research Interview. Medical Education, 40, 314-321. https://doi.org/10.1111/j.1365-2929.2006.02418.x

[29] Lebanese Association of Certified Public Accountants LACPA (2019) Directory. https://www.lacpa.org.lb/directory/practicing-members

[30] Ministry of Economy and Trade MoET (2014) Lebanon SME Strategy: A Roadmap 
to 2020. Inventis.

https://www.economy.gov.lb/public/uploads/files/6833 5879 4642.pdf

[31] Yamane, T. (1967) Statistics: An Introductory Analysis. 2nd Edition, Harper and Row, New York.

[32] Rkein, H., Issa, Z.A., Awada, F.J. and Hejase, H.J. (2019) Impact of Automation on Accounting Profession and Employability: A Qualitative Assessment from Lebanon. Saudi Journal of Business Management, 4, 372-385.

[33] Lupasc, A., Lupasc, I. and Zamfir, C.G. (2012) Impact of Intelligent Modern Technologies in Business. Ovidius University Annals Economic Sciences Series, 12, 580-585. https://ideas.repec.org/a/ovi/oviste/v10y2010i1p1695-1699.html

[34] Uwadiae, O. (2015) Financial Reporting Automation. Deloitte. https://www2.deloitte.com/ng/en/pages/audit/articles/financial-reporting/financialreporting-automation-1.html

[35] Alarcon, J.L. and Staut, M.T. (2017) The Internet of Things: The CPA's Role in the New World of Business. Pennsylvania CPA Journal, 1, 26-31.

https://www.picpa.org/articles/picpa-news/2016/11/28/the-internet-of-things-the-c pa-s-role-in-the-new-world-of-business

[36] Taipaleenmäki, J. and Ikäheimo, S. (2013) On the Convergence of Management Accounting and Financial Accounting-The Role of Information Technology in Accounting Change. International Journal of Accounting Information Systems, 14, 321-348. https://doi.org/10.1016/j.accinf.2013.09.003

https://www.researchgate.net/publication/286097180 On the convergence of ma nage-

ment accounting and financial accounting the role of information technology in accounting change

[37] Drum, D.M. and Pulvermacher, A. (2016) Accounting Automation and Insight at the Speed of Thought. Journal of Emerging Technologies in Accounting, 13, 181-186. https://doi.org/10.2308/jeta-51441

[38] Gass, J. (2018) AIS Impact on Accounting and Finance. https://www.forbes.com/sites/theyec/2018/09/10/ais-impact-on-accounting-and-fin ance/\#404fdcc2e855

[39] Dimitriu, O. and Matei, M. (2015) Cloud Accounting. A New Business Model in a Challenging Context. Procedia Economics and Finance, 32, 665-671. https://doi.org/10.1016/S2212-5671(15)01447-1 https://www.researchgate.net/publication/289993037 Cloud Accounting A New Business Model in a Challenging Context

[40] Ionescu, B.S. and Tudoran, E.L. (2013) Financial Information Security in the Cloud. Annales Universitatis Apulensis Series Oeconomica, 15, 443-449.

[41] Ionescu, B.S., Prichici, C. and Tudoran, L. (2014) Cloud Accounting-A Technology That May Change the Accounting Profession in Romania. Audit Financiar Journal, 12, 3-15.

[42] Deloitte (2016) Transformers: How Machines Are Changing Every Sector of the UK Economy.

https://www2.deloitte.com/content/dam/Deloitte/uk/Documents/technology-media -telecommunications/deloitte-uk-transformers-2016.pdf

[43] Vermeulen, B., Kesselhut, J., Pyka, A. and Saviotti, P.P. (2018) The Impact of Automation on Employment: Just the Usual Structural Change? Sustainability, 10, 1661-1687. https://doi.org/10.3390/su10051661 